UDK: 331.45/.46

DOI: https://doi.org/10.24867/11HZ01Antic

\title{
ANALIZA OPASNOSTI I PROCENA RIZIKA NA RADNOM MESTU RUKOVAOCA HIDRAULIČNOM PRETOVARNOM DIZALICOM
}

\section{HAZARD ANALYSIS AND WORKPLACE RISK ASSESSMENT FOR THE HYDRAULIC LOADER CRANE OPERATOR}

\author{
Nataša Antić, Fakultet tehničkih nauka, Novi Sad
}

\begin{abstract}
Oblast - INŽENJERSTVO ZAŠTITE NA RADU
Kratak sadržaj - Zadatak rada jeste procena rizika po bezbednost $i$ zdravlje na radu prilikom rada sa hidrauličnom pretovarnom dizalicom. Nakon procene rizika, propisane su odgovarajuće preventivne mere za bezbedan i zdrav rad pri radu sa dizalicom, zajedno sa kratkim uputstvom za bezbedan rad. Stručni nalaz hidraulične pretovarne dizalice obrađen je po uzoru na već gotove stručne nalaze, u skladu sa Pravilnikom o postupku pregleda i provere opreme za rad $i$ ispitivanje uslova radne okoline (,,Sl. glasnik RS“, br. 94/2006, 108/2006 - ispr., 114/2014 i 102/2015).
\end{abstract}

Ključne reči: Hidraulična pretovarna dizalica, bezbednost $i$ zdravlje na radu, procena rizika, pregled $i$ provera opreme za rad

\begin{abstract}
The purpose of the paper is the risk assessment of the health and safety at work while working with hydraulic loader crane. After assessing the risk, appropriate preventive measures for healthy and safe work were prescribed, together with a brief health and safety manual. The expert finding of the hydraulic loader crane was processed according to the model of already finished expert findings, according to the Regulation of examination and testing of work equipment and investigation of work environment conditions (,, Official gazette of $R S^{\prime}$, no. 94/2006, 108/2006 - corr., 114/2014 and 102/2015).
\end{abstract}

Keywords: Hydraulic loader crane, health and safety at work, risk assessment, examination and testing of work equipment

\section{UVOD}

Ovaj rad predstavlja nastavak diplomskog rada Mere bezbednosti $i$ zdravlja na radu sa hidrauličnim pretovarnim dizalicama, [1].

Hidraulična pretovarna dizalica (sl. 1) je dizalica ugrađena na teretno vozilo odgovarajuće šasije, u svrhu utovara i istovara tog vozila. Upotreba hidraulične pretovarne dizalice zastupljena je najviše pri građevinskim i komunalnim radovima, radovima održavanja, fasadnim i elektromonterskim radovima i sl.

\footnotetext{
NAPOMENA:

Ovaj rad proistekao je iz master rada čiji mentor je bio dr Atila Zelić, docent.
}

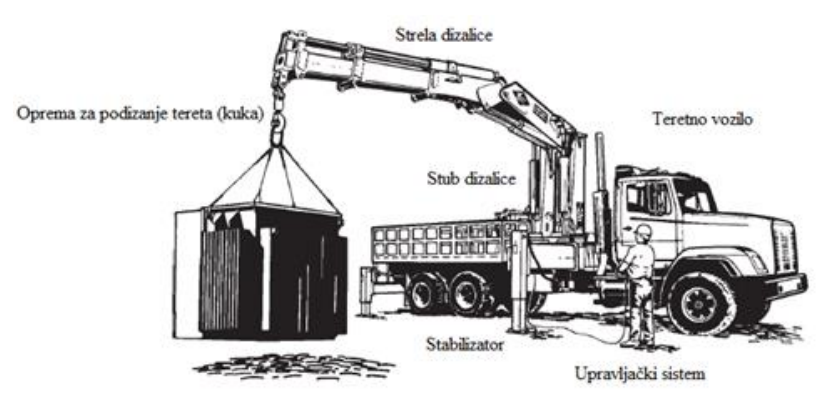

Slika 1. Hidraulična pretovarna dizalica sa kukom

Cilj rada jeste da se proširi već obrađena tematika diplomskog rada [1], u vidu procene rizika po bezbednost $\mathrm{i}$ zdravlje na radu prilikom rada sa hidrauličnom pretovarnom dizalicom, kao i pregleda i provere iste, sa formiranim stručnim nalazom o bezbednoj upotrebi.

Inicijalnim zadatkom ovog rada definisan je i praktični pregled i provera hidraulične pretovarne dizalice u odabranom preduzeću, ali zbog propisanih preventivnih mera sprečavanja širenja virusa Covid 19, u periodu izrade rada ova aktivnost nije realizovana. Pošto praktični deo rada nije bilo moguće izvesti, u master radu dat je samo blanko primer nalaza. Stručni nalaz koncipiran je na osnovu relevantnih pravilnika i primera drugih stručnih nalaza.

\section{PREGLED VAŽEĆE REGULATIVE}

Kada se govori o eksploataciji, kao i o bezbednosti zdravlju pri radu sa hidrauličnom pretovarnom dizalicom, relevantni su sledeći standardi:

$$
\begin{array}{ll}
\text { - } & \text { ISO 15442:2012, [2]; } \\
\text { - } & \text { ISO 21308-5:2014, [3]; } \\
\text { - } & \text { BS 7121-4:2010, [4]. }
\end{array}
$$

Prioritet prilikom upotrebe $\mathrm{za}$ rad ima bezbednost i zdravlje na radu, odnosno ISO 15442:2012, standard tipa C. Standard se odnosi na minimalne zahteve vezane za projektovanje, proračune, preglede i provere hidrauličnih dizalica i njihovih nosača na šasiji ili nepokretnoj podlozi.

Standard ISO 21308-5:2014, odnosi se na ugradnju pretovarne dizalice na teretno vozilo, odgovarajući sistem kodiranja i koordinatne sisteme delova konstrukcije, kao i njihove transformacije u odgovarajući sistem radi pogodne montaže delova konstrukcije.

Britanski standard BS 7121-4:2010, odnosi se takođe na zahteve za bezbednosti i zdravlja na radu. 


\section{OPASNOSTI I ŠTETNOSTI KOJE SE JAVLJAJU PRI RADU SA HIDRAULIČNOM PRETOVARNOM DIZALICOM}

U Aneksu A standarda ISO 15442:2012, data je lista važnijih opasnosti, kao i situacija i događaja koji mogu dovesti do rizika po zdravlje i bezbednost zaposlenog osoblja prilikom rada sa hidrauličnom pretovarnom dizalicom (tab. 1).

Tabela 1. Lista opasnosti i štetnosti, [2]

\begin{tabular}{|l|}
\hline \multicolumn{1}{|c|}{ Opasnosti i štetnosti } \\
\hline $\begin{array}{l}\text { Mehaničke opasnosti vezane za neadekvatnu } \\
\text { mehaničku čvrstoću dizalice i njenih delova } \\
\text { (drobljenje, smicanje, uplitanje, udar, probadanje, } \\
\text { gubitak stabilnosti i slično) }\end{array}$ \\
\hline $\begin{array}{l}\text { Električne opasnosti (direktni kontakt, indirektni } \\
\text { kontakt, toplotno zračenje i slično) }\end{array}$ \\
\hline $\begin{array}{l}\text { Toplotne opasnosti, zbog kojih nastaju opekotine i } \\
\text { oštećenja zdravlja }\end{array}$ \\
\hline Opasnosti prouzrokovane bukom \\
\hline Opasnosti prouzrokovane vibracijama \\
\hline $\begin{array}{l}\text { Opasnosti prouzrokovane materijalima i supstan- } \\
\text { cama koje nastaju ili se koriste od strane mašine }\end{array}$ \\
\hline $\begin{array}{l}\text { Opasnosti prouzrokovane zanemarivanjem } \\
\text { ergonomskih principa u konstrukciji mašine }\end{array}$ \\
\hline Neočekivano pokretanje, neočekivana brzina \\
\hline $\begin{array}{l}\text { Opasnosti prouzrokovane nedostatkom i/ili } \\
\text { nekorektnim postavljanjem sredstava za zaštitu }\end{array}$ \\
\hline Greške pri montaži \\
\hline Gubitak stabilnosti/preturanje mašine \\
\hline
\end{tabular}

U skladu sa prethodno navedenim opasnostima i štetnostima u tab. 1, može se sprovesti adekvatna procena rizika po bezbednost i zdravlje na radu, što je i objašnjeno u narednoj tački rada.

\section{PROCENA RIZIKA PO BEZBEDNOST I ZDRAVLJE NA RADU SA HIDRAULIČNOM PRETOVARNOM DIZALICOM}

Pravilnikom o načinu i postupku procene rizika na radnom mestu i u radnoj okolini [8], utvrđuje se način i postupak procene rizika od nastanka povreda na radu ili oštećenja zdravlja, odnosno oboljenja zaposlenog na radnom mestu i u radnoj okolini, kao i način za njihovo otklanjanje, koje poslodavac uređuje Aktom o proceni rizika. Procenjivanje rizika se vrši za svaku prepoznatu opasnost ili štetnost, upoređivanjem sa dozvoljenim vrednostima $u$ odgovarajućim propisima bezbednosti $i$ zdravlja na radu, tehničkim propisima, standardima i preporukama. Ukoliko nakon primenjenih mera u oblasti bezbednosti i zdravlja na radu, radno mesto i dalje predstavlja rizik, tada se Aktom o proceni rizika to mesto proglašava radnim mestom sa povećanim rizikom, za koje procenjivači rizika moraju dati obrazloženje zbog kojih se opasnosti i štetnosti to radno mesto vodi kao mesto sa povećanim rizikom, [5].

\subsection{Akt o proceni rizika}

Dva osnovna zakona na osnovu kojih se izađuje Akt o proceni rizika su Zakon o bezbednosti i zdravlju na radu [6] i Pravilnik o načinu i postupku procene rizika na radnom mestu i u radnoj okolini [8].
Akt o proceni rizika sastoji se iz opisanih procesa rada odgovarajućeg radnog mesta za svako radno mesto, sa procenom rizika od povreda ili oboljenja na datom radnom mestu i merama za njihovo otklanjanje ili smanjenje rizika u cilju unapređivanja bezbednosti i zdravlja na radu. Akt podleže potpunoj izmeni i dopuni nakon svake kolektivne povrede na radu sa smrtnim posledicama, a delimičnim izmenama i dopunama podleže u slučaju:

- smrtne i teške povrede na radu,

- svake nove opasnosti ili štetnosti (tj. promene nivoa rizika),

- kada mere koje su utvrđene za sprečavanje, otklanjanje ili smanjenje rizika nisu odgovarajuće,

- kada je procena zasnovana na zastarelim podacima,

- kada postoji mogućnost i način za unapređenje (tj. dopunu procenjivanja rizika).

\subsection{Metode procene rizika}

Prema [9], u zavisnosti od vrste podataka koje koriste, metode procene rizika mogu biti: kvalitativne, kvantitativne i kombinovane, odnosno polukvantitativne. Dele se na metode za procenu verovatnoće, koje za cilj imaju identifikaciju i kvantifikaciju područja potencijalnog rizika, i metode za procenu posledica, koje za cilj imaju procenu negativnih posledica, njihovih efekata i opis potencijalnih mera zaštite za eliminaciju tih efekata.

Kvalitativne metode koriste kvalitativne podatke, samim tim se i rezultat ocene dobija kao kvalitativna veličina. Takođe, kvalitativnim metodama procenjuje se primena i poštovanje kriterijuma koje definišu standardi, zakoni, propisi i norme.

Kvantitativne metode koriste kvantitativne podatke i podrazumevaju poznavanje verovatnoće neželjenog događaja, do koje se dolazi na osnovu istorijskih podataka, primene analitičkih tehnika ili ekspertnih ocena. Neophodno je i poznavanje kvantitativnih vrednosti očekivanih posledica realizacije ovog događaja. Kvantitativna mera rizika najćešće se određuje kao proizvod vrednosti navedenih veličina.

Polukvantitativne metode zasnivaju se na sudovima eksperata. Kada nije moguće oceniti verovatnoću prilikom retkih događaja, kao ni veličinu posledica (koje mogu biti različite za različite uslove), ove veličine procenjuju se i rangiraju na osnovu skala verovatnoće i posledica, koje se najčešće određuju kao proizvod ili zbir mera verovatnoće i potencijalnih efekata.

\subsubsection{Kinney metoda procene rizika}

Prema Kinney metodi procene rizika, rizik $R$ se određuje upotrebom obrasca:

$$
R=V x P x U
$$

gde je sa $V$ označena verovatnoća nastanka događaja, sa $P$ posledica, tj. težina moguće povrede ili oboljenja, dok oznaka $U$ predstavlja učestalost izlaganja događajima ( $\mathrm{tj}$. opasnostima i/ili štetnostima).

Iako postoje mnogobrojne metode procene rizika, za procenu rizika u ovom radu upotrebljena je Kinney metoda, usled česte zastupljenosti u ovoj oblasti i značajne efikasnosti u primeni. 


\subsection{Procena rizika radnog mesta za rukovaoca hidrauličnom pretovarnom dizalicom}

Prilikom rada sa hidrauličnom pretovarnom dizalicom prvenstveno je moguć nastanak mehaničkih opasnosti u vidu: zaglavljivanja, udara, kolapsa (usled neadekvatne mehaničke čvrstoće dizalice i njenih delova); gubitka stabilnosti dizalice usled neadekvatne podloge i nebezbednog postavljanja stabilizatora; povreda zaposlenih usled izbacivanja radne tečnosti pod visokim pritiskom iz hidrauličnog sistema; klizanja, saplitanja i pada usled curenja hidrauličnog ulja, itd. Opasnosti se javljaju i prilikom transporta do radnog mesta, poput udara u delove saobraćajne infrastrukture, usled neadekvatnog slaganja pretovarne dizalice.

Javljaju se i opasnosti prilikom neadekvatne pozicije rukovaoca (prilikom čega ne postoji potpun vizuelni pregled manipulacionog prostora), kao i pri prostornim ograničenjima. Sve ovo može da dovede do neadekvatnog izvođenja radnog zadatka i dodatnog psihičkog opterećenja rukovaoca. $\mathrm{Ne}$ treba zaboraviti ni na mogućnost preturanja dizalice usled nekontrolisanog prekoračenja momenta stabilnosti, nekontrolisanim obimom pokretanja ili neočekivanim kretanjem tereta, kao ni na probleme zbog izbora neadekvatnih zahvatnih sredstava i opreme za vezivanje/vešanje tereta.

Opasnosti koje se pojavljuju u vezi sa karakteristikama radnog mesta odnose se na uslove radne podloge prilikom različitih vremenskih uslova, pri čemu može doći do neadekvatnog postavljanja opreme za rad, kao i klizanja i pada radnika po klizavim površinama usled snega, kiše i slično. Takođe, opasnosti se mogu javiti i usled nevremena i udara groma. Električne opasnosti, odnosno opasnosti koje se pojavljuju korišćenjem električne energije, javljaju se u vidu opasnosti od direktnog dodira sa delovima električne instalacije i opreme pod naponom (kao što su npr. upravljački uređaji ili nadzemni strujni vodovi), u slučaju oštećenih instalacija, nepropisno izvedenih instalacija, neprikladne opreme i tome slično, potom opasnosti od toplotnog dejstva koje razvijaju električna oprema i instalacije kao što su pregrevanja, varničenja i požari. Električne opasnosti javljaju se i prilikom transporta, u slučaju neadekvatnog slaganja dizalice na teretni prostor vozila, prilikom čega dolazi do kidanja nadzemnih strujnih vodova.

Javljaju se i štetnosti koje nastaju ili se pojavljuju u procesu rada poput oštećenja zdravlja prilikom rada pri visokim ili niskim temperaturama, visoka ili niska vlažnost, veća brzina strujanja vazduha, rad na otvorenom prilikom čega dolazi do izlaganja IC i UV zračenju, kao i buka koja se javlja prilikom rada i usled radova koji se obavljaju u bližoj okolini i štetnosti u vidu prašine koje se javlja usled uslova rada na prašnjavim površinama ili sa materijalima koji proizvode prašinu.

Štetnosti koje proističu iz psihičkih i psihofizioloških napora koji se uzročno vezuju za radno mesto i poslove poput nefiziološkog položaja tela, odnosno dugotrajnog stajanja pri upravljanju hidrauličnom petovarnom dizalicom ili dugotrajnog sedenja pri transportu do radnog mesta, kao i odgovornost u primanju i prenošenju informacija i korišćenje odgovarajućih znanja i sposobnosti. Pored toga, neretko se javlja i mogućnost prekovremenog rada.
Procenom rizika metodom Kinney, izveden je zaključak da radno mesto rukovaoca hidrauličnom pretovarnom dizalicom nije radno mesto sa povećanim rizikom. Međutim, na bezbednost i zdravlje prilikom upravljanja dizalicom utiču brojni faktori. S obzirom da je hidraulična pretovarna dizalica $\mathrm{u}$ većini slučajeva postavljena na teretno vozilo, menjanje lokacije rada je frekventno i stanja radnih podloga su različita. Neretko se radovi odvijaju u blizini obale, nasipa ili na terenu pod nagibom, što značajno utiče na stabilnost dizalice. Takođe, prilikom rada ne treba zaboraviti na vremenske uslove, kao ni na ograničenja u urbanim sredinama. U takvim slučajevima, rizik se može okarakterisati kao povišen, sa mogućim katastrofalnim posledicama po život rukovaoca i radnika $\mathrm{u}$ blizini dizalice.

\subsubsection{Preporučene preventivne mere prema potencijalnim opasnostima i štetnostima}

Prema potencijalnim opasnostima i štetnostima, propisane su preventivne mere poput:

- svakodnevna provera ispravnosti delova hidraulične pretovarne dizalice, pojačana opreznost pri radu;

- ispitivanje podloge pre početka rada, odnosno pre postavljanja stabilizatora; postavljanje stabilizatora po odgovarajućem uputstvu proizvođača;

- svakodnevna provera hidrauličnog sistema i hidrauličnih creva na mehanička oštećenja (popravka/zamena odmah nakon uočavanja oštećenja i zaustavljanje rada dok se ne otklone smetnje ili ne poboljšaju okolnosti rada;

- zabrana prisustva nezaposlenim licima;

- obezbeđivanje signaliste koji će olakšati rukovaocu rukovanje dizalicom;

- slaganje dizalice na teretno vozilo prema uputstvima proizvođača i ne započinjati transport pre provere adekvatne složenosti dizalice (pre slaganja dizalice proveriti rad uređaja koji prate stanje i položaj slaganja segmenata konstrukcije dizalice);

- provera ispravnosti uzemljenja teretnog vozila i hidraulične pretovarne dizalice i obustava rada prilikom olujnog vremena;

- upotreba vizuelnog menadžmenta, odnosno postavljanje nalepnica na delove dizalice u cilju podsećanja zaposlenih na opasnosti;

- upotreba lične zaštitne opreme poput zaštitnog šlema, radnog odela, zaštitnih cipela, zaštitnih rukavica, zaštitnih naočara, itd.

\section{PREGLED I PROVERA HIDRAULIČNE PRETOVARNE DIZALICE}

Lokacija ispitivanja mora biti izvan javnih mesta, kao što su putevi, pruge, fabrike i posedstva, koja osim što ometaju ispitivanje, mogu biti i ugroženi. Lokacija na kojoj se obavlja ispitivanje ne sme da bude izložena čestim i naglim vremenskim promenama (ispitivanje se nikada ne obavlja po kiši, snegu, u magli i slično). Područje ispitivanja mora biti ograđeno i označeno tablom za zabranu pristupa neovlašćenim licima. Podloga za ispitivanje mora bit stabilna, dovoljno čvrsta i ravna, sa maksimalno $\pm 0,5^{\circ}$ nagiba. Prostor iznad dizalice mora biti slobodan i prostran, kako bi se kretanja dizalice vršila neometano. 
Prema međunarodnom standardu, ISO 15442:2012, ispitivanje se vrši pri brzini vetra manjoj od $30 \mathrm{~km} / \mathrm{h}$, sa pritiskom u pneumaticima koji je propisan od strane proizvođača, a sama dizalica treba da je postavljena $i$ upravljana prema instrukcijama proizvođača datim $u$ uputstvu za rad.

Nakon detaljnog pregleda, vrši se probno statičko i probno dinamičko ispitivanja dizalice, kao i ispitivanje stabilnosti vozila, pri kritičnom položaju srele i merodavnom stanju podloge u odnosu na nagib terena. Provera se smatra uspešnom ukoliko pri dignutom probnom teretu nisu uočena mehanička oštećenja delova konstrukcije dizalice, odnosno nije došlo do pojave otkaza upravljačkih/ pogonskih/bezbednosnih sistema ili preturanja same dizalice.

Pregled i proveru izvodi pravno lice sa licencom za obavljanje poslova pregleda i provere opreme za rad, koje poseduje odgovarajuće instrumente i uređaje za vršenje pregleda i provere, navedene sa tehničkim karakteristikama u prihvaćenoj metodologiji. Prilikom izdavanja stručnog nalaza, pravno lice koje je obavilo pregled i proveru, prilaže kopiju licence tog pravnog lica i odgovornog lica koje je potpisalo stručni nalaz. Izveštaj o pregledu i proveri treba da bude dostavljen i čuvan na sigurnom mestu, odnosno na mestu eksploatacije dizalice, a obavezno i u kabini vozila.

Preventivni pregledi i provere opreme za rad, izvode se:

- pre početka korišćenja, odnosno pre davanja na upotrebu zaposlenima;

- posle rekonstrukcije ili havarije;

- pre početka rada na novom mestu, odnosno u slučaju prebacivanja dizalice sa jednog teretnog vozila na drugo.

Periodični pregledi i provere opreme za rad obavljaju se u roku utvrđenom tehničkim propisima i standardima ili uputstvom proizvođača, a najkasnije u roku od 3 godine od dana prethodnog pregleda i provere [7].

Inicijalnim zadatkom ovog master rada, bila je predviđena i izrada stručnog nalaza na osnovu pregleda i provere konkretne hidraulične pretovarne dizalice. Međutim, usled neočekivanog uvođenja vanrednog stanja i mera sprečavanja širenja virusa Covid 19, ove terenske aktivnosti nisu realizovane, pa je u master radu dat samo nepopunjeni model stručnog nalaza.

\section{ZAKLJUČAK}

Usled rasprostranjene upotrebe hidraulične pretovarne dizalice na teretnim vozilima, neophodno je izvršiti određene procene, preglede i provere, predviđene zakonskom regulativom.

Sagledavanjem rizika, mogu se propisati realne mere zaštite koje će taj rizik smanjiti na najmanju moguću meru. Smanjivanjem rizika, smanjuje se i broj povreda na radu, odnosno broj radnih dana koji će time biti uskraćeni, a postiže se psihičko blagostanje zaposlenog $u$ vidu sigurnog i bezbednog izvođenja radnog zadatka i očuvanja fizičkog zdravlja.
Iako procenom rizika (u većini slučajeva u praksi) radno mesto rukovaoca hidrauličnom pretovarnom dizalicom nije utvrđeno kao radno mesto sa povećanim rizikom, preporučuje se (zakonski neobavezni) lekarski pregled, kako bi se utvrdile pogodne funkcije zaposlenog koji radi kao rukovalac dizalice, poput vida, sluha, brzine reagovanja, sporazumevanja i druge kognitivne funkcije. Lekarskim pregledom i adekvatnom obukom zaposlenog za bezbedan i zdrav rad (najmanje jednom u tri godine), postiže se najveća moguća sigurnost pri izvođenju radnog zadatka, pored obezbeđenja ispravne opreme za rad i lične zaštitne opreme zaposlenog.

\section{LITERATURA}

[1] Nataša Antić: Mere bezbednosti i zdravlja na radu sa hidrauličnim pretovarnim dizalicama, diplomski rad, Fakultet tehničkih nauka, Novi Sad, 2019.

[2] ISO 15442:2012: Cranes - Safety requirements for loader cranes, Geneva, 2012.

[3] ISO 21308-5:2014: Road vehicles - Product data exchange between chassis and body work manufacturers (BEP) - Part 5: Coding of loader crane bodywork, Geneva, 2014.

[4] BS 7121-4:2010: Code of practice for safe use of cranes - Part 4: Lorry loaders, London, 2010.

[5] Jocić Neda: Vodič za procenu i upravljanje rizikom: bezbednost i zdravlje na radu, „Futura“, Petrovaradin, Novi Sad, 2008.

[6] Zakon o bezbednosti i zdravlju na radu (,Sl. glasnik RS“, br. 101/2005, 91/2015 i 113/2017 - dr. zakon)

[7] Pravilnik o postupku pregleda i provere opreme za rad $\mathrm{i}$ ispitivanja uslova radne okoline (,Sl. glasnik RS“, br. 94/2006, 108/2006 - ispr., 114/2014 i 102/2015)

[8] Pravilnikom o načinu i postupku procene rizika na radnom mestu i u radnoj okolini (,Sl. glasnik RS“, br. 72/2006, 84/2006 - ispr., 30/2010 i 102/2015)

[9] Miroljub D. Grozdanović, Evica I. Stojiljković: Metode procene rizika, Fakultet zaštite na radu u Nišu, Niš, 2013.

\section{Kratka biografija:}

Nataša Antić rođena je u Novom Sadu 1996. godine. Na Fakultetu tehničkih nauka iz oblasti Inženjerstva zaštite na radu diplomirala je 2019. godine, a master rad odbranila 2020. godine na temu Analiza opasnosti i procena rizika na radnom mestu rukovaoca hidrauličnom pretovarnom dizalicom.

kontakt: anticnatasa96@gmail.com 